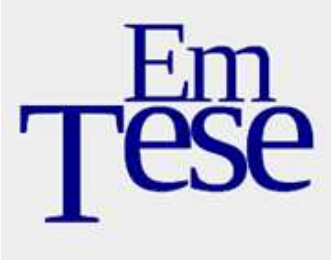

\title{
Direito de morte e dever de vida: a mídia como canal de tecnologias políticas
}

\section{Jeferson Bertolini ${ }^{1}$}

\section{Introdução}

Amarrado a uma estaca de madeira, Rodrigo Gularte foi executado com tiros de fuzil em uma ilha da Indonésia na madrugada de 28 de abril de 2015 . O brasileiro de 42 anos, condenado por tráfico de drogas, vestia uma camiseta branca com um " $\mathrm{x}$ " preto no peito para facilitar o trabalho dos atiradores. Só policiais, médicos e religiosos testemunharam os disparos. A imprensa foi mantida a distância. Mas a notícia correu o mundo com um recado implícito: aquele que transgride a lei ainda paga com a vida.

$\mathrm{Na}$ mesma ilha, três meses antes, outro brasileiro havia sido fuzilado por cometer o mesmo crime. Marco Archer Cardoso Moreira, 53 anos, levou um tiro de fuzil no peito. A morte foi declarada por um médico 10 minutos depois do disparo. Outra vez os jornalistas foram mantidos afastados. Mas outra vez a notícia da execução espalhou-se mundo afora com seu recado intimidador.

As mortes de Rodrigo Gularte e de Marco Archer mostram que, em algumas regiões do mundo, o suplício do século 18 ainda não foi abolido. A diferença é que atualmente o soberano não mata mais diante do pequeno grupo na praça; mata na frente do grande público, via meios de comunicação: o direito de morte, com a intenção de medo que lhe é inerente, cruza fronteiras e atinge a massa!

Além do suplício, outra tecnologia política vale-se da mídia nestes tempos de overdose informacional (POSTMANN, 2004) para atingir o grande público: o dever de

\footnotetext{
${ }^{1}$ Doutorando em Ciências Humanas (UFSC). Mestre em Jornalismo (UFSC) e Bacharel em Comunicação Social/Jornalismo (Univali). É bolsista Capes. Contato: jefersonbertolini@gmail.com.
} 


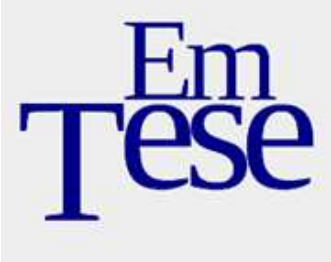

causar a vida. Por meio deste dever, o soberano dos dias de hoje busca ampliar as forças do corpo dos súditos em termos de utilidade econômica e diminuir essas mesmas forças em termos de mobilização política.

Este artigo aborda as execuções dos dois brasileiros na Indonésia para costurar dois temas marcantes da obra de Foucault: (1) o suplício, pelo qual o soberano faz uma demonstração de força explícita para tornar os súditos dóceis por meio da intimidação; e (2) o biopoder, pelo qual faz uma valorização da vida ante à morte visando o bom andamento da economia política.

O texto baseia-se em levantamento bibliográfico, básico ao trabalho científico porque "permite ao pesquisador conhecer o que já se estudou sobre o assunto" (FONSECA, 2002, p. 32). O ensaio tem proposta de associar estudos da Sociologia e da mídia por meio de técnica interdisciplinar, usada sempre que topamos com um objeto “cujo lugar não está traçado no grande mapa dos saberes” (POMBO, 2007, p. 6).

O manuscrito está divido em cinco partes, a partir da introdução. A primeira destaca o suplício. A segunda, o biopoder. A terceira aborda os dois eixos do biopoder: a disciplina dos corpos e a biopolítica da raça humana. A quarta mostra que o conteúdo de caráter biopolítico apresentado pela mídia cria uma realidade assimilada pelo público (LUHMANN, 2005). A quinta traz as considerações finais.

O ensaio conclui que o direito de causar a morte fundamenta uma nova estratégia política, a do dever de causar a vida. E sugere que este fenômeno impõe às sociedades modernas (1) um novo habitus (BOURDIEU, 2005), por meio do qual os indivíduos aprendem a rejeitar aquilo que causa a morte, como uma alimentação desregrada, e a adotar aquilo que promova a vida, como exercícios físicos; e (2) um novo tipo de racismo, que classifica como normal e dominante aquele que tem o corpo economicamente saudável.

\section{Suplício: O direito de morte operado pelo soberano}


Até o século 18, aquele que violasse a lei em países europeus sofria a pena do crime no próprio corpo: o infrator podia ser decapitado, queimado com óleo quente, destroncado por cavalos ou ter de beber veneno. A pena era aplicada em público para servir de exemplo. Nestes termos, ao exercer o direito de morte sobre o transgressor, o soberano indiretamente exercia um direito de vida sobre os súditos: para escapar dos castigos que assistiam em praça pública, eles deveriam seguir sempre o bom caminho, sendo comportados e dóceis.

No século 19, devido à crueldade das penas, o suplício foi extinto em países como França, Inglaterra e Rússia. O sistema penal nesses países foi reformado, inspirou outras nações mundo afora, e chegou ao formato atual mais usual: a pena recai sobre um direito do infrator (a liberdade); é cumprida em local fechado (agora basta ao público saber que o infrator cumpre a pena); é aplicada pelo juiz (para se diferenciar do carrasco do suplício, o magistrado conta com um exército técnico, com médicos, psiquiatras, psicólogos e seus laudos); e busca reeducar o infrator em vez de castigá-lo (é preciso, por exemplo, recuperá-lo para o trabalho, o sentido da vida no modelo capitalista).

Em nossas sociedades, os sistemas punitivos devem ser recolocados em uma certa economia política do corpo: ainda que não recorram a castigos violentos e sangrentos, mesmo quando utilizam métodos suaves de trancar e corrigir, é sempre do corpo que se trata - do corpo e de suas forças, da utilidade e da docilidade delas, de sua repartição e de sua submissão (FOUCAULT, 2013, p. 28).

O suplício fazia parte do sistema legal da época. Não era, em teoria, uma pena arbitrária, como frequentemente se observava na Antiguidade e na Idade Média, quando se aplicava penas ante as quais a crucificação poderia ser considerada um castigo leve. Como era previsto em lei, muitos governos tinham até um código que estabelecia o tipo de pena (se chibatadas, pedradas, ácido, corte dos tendões) de acordo com cada crime. Este tipo de castigo não era aplicado a todas as infrações. Destinava-se àquelas de maior repercussão, pois assim a demonstração de força do soberano seria ampliada. 
Em regra, o suplício deveria levar em conta uma investigação. Afinal, já se tinha uma ideia de inquérito desde a Idade Média, quando se estabeleceu que julgar era estabelecer a verdade de um crime; para tanto era preciso conhecer a infração, conhecer seu autor e ter conhecimento e aplicação da lei. Foucault (2013) observa que o suplício "se inseriu na prática judicial porque é revelador da verdade e agente do poder".

O suplício promove a articulação do escrito com o oral, do secreto com o público, do processo de inquérito com a operação de confissão; permite que o crime seja reproduzido e voltado contra o corpo visível do criminoso. Faz com que o crime, no mesmo horror, se manifeste e se anule. Faz também do corpo do condenado o local de aplicação da vindita soberana, o ponto sobre o qual se manifesta o poder, a ocasião de afirmar a dissimetria das forças (FOUCAULT, 2013, p. 23).

O pensador francês observa que os reformadores do sistema penal do século 18 passaram a ver no pior dos assassinos uma coisa que deveria ser respeitada no momento da punição: sua humanidade. $\mathrm{E}$ isso fez prevalecer a recuperação do infrator ante o castigo do corpo. "A pena não mais se centralizava no suplício como técnica de sofrimento; tomou como objeto a perda de um bem ou de um direito", observa o autor. "Porém, castigos como trabalhos forçados ou prisão - privação pura e simples de liberdade - nunca funcionaram sem certos complementos punitivos referentes ao corpo: redução alimentar, privação sexual, expiação física, masmorra" (Ibid, p. 20).

A experiência da Indonésia, que castiga com morte por fuzilamento os presos no país por tráfico de drogas, mostra que a tática inicial do suplício ainda perdura em algumas regiões do mundo. O objetivo é o mesmo do século 18: castigar o infrator para servir de exemplo. Ao matar traficantes, o soberano moderno articula a velha técnica do fazer morrer (o infrator) para deixar viver (o cidadão de bem).

Marco Archer, executado em 18 de janeiro de 2015, foi condenado à pena de morte em 2004, um ano depois de entrar no país asiático com 13 kg de cocaína e ser preso pela polícia local. Archer era carioca. No Brasil apresentava-se como instrutor de voo livre. Pelos advogados e em vídeos gravados na cadeia, pediu clemência ao governo 


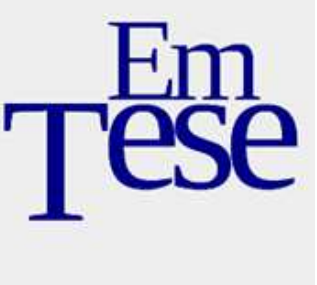

indonésio, dizendo que não poderia pagar com a vida pelo crime que cometera. Não foi atendido. A morte dele abalou as relações diplomáticas entre Brasil e Indonésia.

Rodrigo Gularte, morto em 28 de abril do mesmo ano, foi preso em 2004 ao tentar entrar na Indonésia com $6 \mathrm{~kg}$ de cocaína escondidos em pranchas de surfe. A condenação à morte ocorreu em 2005. O governo da presidente Dilma Rousseff também apelou ao governo indonésio para livrá-lo da morte. Mas os pedidos foram ignorados.

Em nosso tempo, o suplício como forma de intimidação ainda é praticado por Estados $^{2}$ legalmente constituídos, como a Indonésia; também é recurso de grupos marginais, como o Estado Islâmico, que busca poderes indivisíveis e ilimitados ${ }^{3}$ para governar - como forma de intimidação e de demonstração de força, o grupo exibe na internet e na televisão as decapitações dos inimigos.

\section{Biopoder: surge o dever de causar a vida}

O poder soberano, como ocorre na Indonésia até os dias de hoje, é inspirado na pátria potestas, um mecanismo do direito que concedia ao pai de família romano o direito de dispor da vida dos filhos, uma vez que a tinha dado. Com o desenvolvimento das sociedades, o poder soberano foi substituído por uma tecnologia mais sutil de controle da morte e da vida: o biopoder. Trata-se de uma forma de governar a vida que opera em dois eixos: as disciplinas (atuam sobre o corpo dos indivíduos) e a biopolítica (age sobre o conjunto da população).

\footnotetext{
${ }^{2}$ Em definição de Weber (1979), Estado é a comunidade humana que, dentro de determinado território, reclama para si o monopólio da violência física legítima. O Estado é uma relação de dominação de homens sobre homens que, para existir, precisa que os dominados acatem a autoridade que pretendem ter — fazem isso pela autoridade tradicional (como a exercida pelos patriarcas), pela autoridade da graça (carisma) ou pela legalidade (princípios legais).

${ }^{3}$ Dois termos atribuídos ao Estado por Hobbes (2003). Em Leviatã, obra na qual apresenta o contrato social, o autor defende um poder único para representar o povo. O tratado foi escrito durante a Guerra Civil inglesa (1642-1651), que culminou na morte do rei Carlos I. É neste contexto que visualizou o surgimento de uma criatura (o Estado) com poderes "indivisíveis e ilimitados" para livrar o povo da barbárie do estado de natureza.
} 
Foucault (2012, p. 129) diz que, a partir do século 18, o poder de morte se converteu no "complemento de um poder que se exerce positivamente sobre a vida", interferindo em "sua gestão, majoração e multiplicação". Transformou-se no exercício, sobre a vida, "de controles precisos e regulações de conjunto". Como observa o autor, o direito de causar a morte ou deixar viver foi substituído pelo dever de causar a vida. Esse dever sobre a vida desenvolveu-se em duas formas principais.

A primeira, a partir do século 17 , focava o corpo como máquina. Agia na ampliação de suas aptidões, na extorsão de suas forças, no crescimento paralelo de sua utilidade e docilidade, na sua integração em sistemas de controle eficazes e econômicos. Tudo se dava por procedimentos de poder que o autor chama de disciplinas.

A segunda, a partir da segunda metade do século 18, mirou o coletivo. Ou, como define o autor, "no corpo transpassado pela mecânica do ser vivo como suporte dos processos biológicos"; no controle da proliferação, dos nascimentos, da mortalidade, do nível de saúde, da duração da vida, da longevidade com todas as condições que podem fazê-los variar. Tais processos são assumidos mediante toda uma série de intervenções e controles reguladores: uma biopolítica da população.

\begin{abstract}
As disciplinas do corpo e as regulações da população constituem os dois polos em torno dos quais se desenvolveu a organização do poder sobre a vida. A instalação, durante a época clássica, desta tecnologia de duas faces anatômica e biológica -, individualmente e especificante, voltada para os desempenhos do corpo e encarando os processos da vida, caracteriza um poder cuja função mais elevada já não é mais matar, mas investir sobre a vida, de cima para baixo (FOUCAULT, 2012, p.131).
\end{abstract}

É no desenvolvimento rápido, no decorrer da época clássica, das disciplinas diversas, como escolas, colégios e casernas; e no aparecimento, no terreno das práticas políticas e observações econômicas, dos problemas de natalidade, longevidade, saúde pública, habitação e migração; e na explosão de técnicas diversas para se obter a sujeição dos corpos e o controle das populações, que se abre a era do biopoder. 
Para Foucault, este biopoder, "sem a menor dúvida, foi elemento indispensável ao desenvolvimento do capitalismo ${ }^{4}$, que só pôde ser garantido à custa da inserção controlada dos corpos nos aparelhos de produção e por meio de um ajustamento de fenômenos de população aos processos econômicos" (Ibid, p. 132).

\section{Disciplina e Biopolítica: O controle dos corpos}

O biopoder, como destacado na sessão anterior, opera pela (1) disciplina e pela (2) biopolítica O primeiro eixo refere-se aos controles sobre o corpo de cada indivíduo. O segundo, ao conjunto da população (multiplicidade de corpos).

No sistema prisional, que sucedeu o suplício nos mecanismos punitivos, a (1) disciplina está no controle dos espaços (cada um em sua cela, cada grupo em uma galeria), do tempo (durmam às $22 \mathrm{~h}$, acordem às $5 \mathrm{~h}$, trabalhem até as $17 \mathrm{~h}$ ) e dos hábitos (tomem banho de sol, trabalhem com afinco). Fora das prisões está em estratégias políticas e econômicas discretas que domesticam comportamentos.

Em Foucault, a ideia de disciplina surge no século 18, quando a figura do soldado despertou nos camponeses europeus a vontade de também serem viris e heroicos. O soldado tinha o biotipo ideal. Aparentava ser valente, vigoroso e corajoso. O modelo corporal se converteu em "algo que se fabrica" e se imita.

De uma massa informe, de um corpo inapto, fez-se a máquina de que se precisa; corrigiram-se aos poucos as posturas: lentamente uma coação

\footnotetext{
${ }^{4}$ Weber (2013, p. 9-11) define o capitalismo como "a força mais significativa de nossa vida moderna". Boltanski \& Chiapello (2009, p. 37-38) afirmam sobre o que chamam de novo espírito do capitalismo: "O capitalismo, sob muitos aspectos, é um sistema absurdo. Os assalariados perderam a propriedade do resultado de seu trabalho e a possibilidade de levar uma vida ativa fora da subordinação (...). O que importa é que uma parte da população que não possui o capital ou o possui em pequena quantidade, para a qual o sistema não é naturalmente orientado, extrai rendimentos da venda de sua força de trabalho (e não da venda de produtos de seu trabalho), pois não dispõe de meios de produção e, para trabalhar, depende da decisão daqueles que os possuem (pois, em virtude do direito de propriedade, estes últimos podem recusar-lhe o uso de tais meios).
} 
calculada percorre cada parte do corpo, assenhoreia-se dele, dobra o conjunto, torna-o perpetuamente disponível, e se prolonga, em silêncio, no automatismo dos hábitos; em resumo, foi expulso o camponês e lhe foi dada a fisionomia de soldado (FOUCAULT, 2012, p. 131).

O corpo foi alvo de uma valorização como nunca se havia visto antes: transformou-se naquilo que o autor chama de objeto de investimentos imperiosos e urgentes. Por outro lado, também se tornou alvo da disciplina, definida na obra foucaultiana como "métodos que permitem o controle minucioso das operações do corpo, que realizam a sujeição constante de suas forças e lhes impõem uma relação de docilidade-utilidade".

Foucault lembra que muitos processos disciplinares existiam havia muito tempo: nos conventos, nos exércitos, nas oficinas. Mas em sua perspectiva as disciplinas se tornaram, no decorrer dos séculos 17 e 18, fórmulas gerais de dominação.

A (2) biopolítica foi percebida com mais nitidez na segunda metade do século 18. Ela não exclui a técnica disciplinar porque "é de outro nível, está em outra escala, tem outra superfície de suporte e é auxiliada por instrumentos totalmente diferentes". Mas "a embute, a integra, a modifica parcialmente e, sobretudo, vai utilizá-la implantando-se de certo modo nela, e incrustando-se efetivamente graças a essa técnica disciplinar prévia".

\begin{abstract}
A disciplina tenta reger a multiplicidade dos homens na medida em que essa multiplicidade pode e deve redundar em corpos individuais que devem ser vigiados, treinados, utilizados, eventualmente punidos. E, depois, a nova tecnologia que se instala (a biopolítica) se dirige à multiplicidade dos homens, não na medida em que eles se resumem em corpos, mas na medida em que ela forma, ao contrário, uma massa global, afetada por processos de conjunto que são próprios da vida, que são processos como o nascimento, a morte, a produção, a doença (FOUCAULT, 2012, p. 289).
\end{abstract}

Para Foucault, a biopolítica se encarregou inicialmente de processos como a proporção dos nascimentos, a taxa de reprodução, a fecundidade de uma população. Para o autor, a biopolítica lida com um novo corpo, um corpo múltiplo, de inúmeras cabeças: a população. "A população como problema político, como problema a um só 


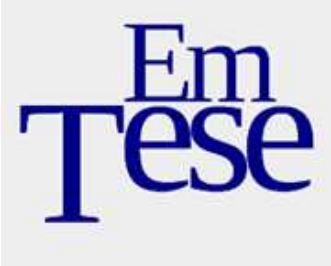

tempo científico e político, como problema biológico e como problema de poder, acho que aparece nesse momento" (Ibid, p. 292-293).

Foucault observa que essa tecnologia de poder criou mecanismos que tratam, sobretudo, de previsões, estimativas estatísticas e medições globais. Em outras palavras, a biopolítica implantou regulações que buscam otimizar um estado de vida: "A soberania fazia morrer e deixava viver. E eis que agora aparece um poder, que eu chamaria de regulamentação, e que consiste, ao contrário, em fazer viver e deixar morrer" (Ibid, p. 294).

\section{Mídia: O soberano moderno fala às massas}

Os meios de comunicação de massa ${ }^{5}$ não existiam no século 18 , quando se aplicava o suplício e quando o biopoder passou a articular a disciplina (para controlar os corpos dos indivíduos) e a biopolítica (para reger o conjunto da população).

Com a mídia, estas tecnologias políticas ${ }^{6}$ ganharam potência e passaram a atingir o grande público: o soberano agora fala diretamente ou indiretamente às massas! Tais tecnologias políticas não têm mais os mesmos contornos que tinham nos séculos 18 e 19. Eles foram reconfigurados. Mas o objetivo delas ainda é o mesmo: reger os indivíduos de forma a torná-los politicamente dóceis e economicamente rentáveis.

Neste contexto, as notícias dos fuzilamentos na Indonésia vão muito além de informar sobre o sistema legal de um país que pune com pena de morte quem trafica drogas; o noticiário ressuscita a ideia do servir de exemplo do suplício: na frente da

\footnotetext{
${ }^{5}$ Os meios de comunicação de massa englobam televisão, rádio, jornal e internet. Juntos formam a mídia. A televisão foi criada em 1925 (ao Brasil, chegou em 1950). O rádio surgiu em 1906 (1922, no Brasil). Os jornais surgiram em 1609, mas só ganharam corpo após a Revolução Industrial e atingiram a massa no século 20. A internet só se popularizou nos anos 1990 (BRIGGS \& BURKE, 2006).

${ }^{6}$ Foucault (2012) também usa o termo tecnologias de poder ou dispositivos de poder.
} 


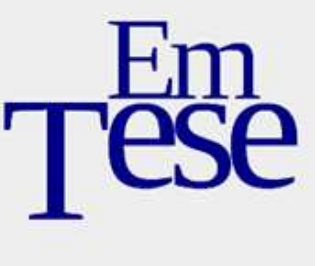

televisão, o público vê o que acontece com quem viola a lei; associa droga à morte; volta-se, então, àquilo que promove a vida, que faz viver.

Nesta dualidade entre aquilo que mata e aquilo que faz viver, os meios de comunicação entram em uma espiral biopolítica. Eles informam sobre os riscos de (1) aproximar-se daquilo que mata e de (2) afastar-se daquilo que faz viver!

Na perspectiva de Kovach \& Rosenstiel (2003) a busca por informação é um "instinto básico do ser humano". Por esse motivo, o conteúdo veiculado pelos meios de comunicação é vorazmente consumido e assimilado. "As pessoas precisam saber o que acontece do outro lado do país e do mundo, estar a par de fatos que vão além de sua experiência" porque "o conhecimento do desconhecido lhes dá segurança, permite-lhes administrar suas vidas" (KOVACH \& ROSENSTIEL, 2003, p. 17).

Para Luhmann (2005), os meios de comunicação constroem a realidade. Eles determinam muito do que sabemos do mundo. "Aquilo que sabemos sobre nossa sociedade, ou mesmo sobre o mundo no qual vivemos, o sabemos pelos meios de comunicação" (Ibid, p. 15). Em "termos kantianos", complementa o autor, significa dizer que eles "produzem uma ilusão transcendental" (Ibid, p. 20).

Luhmann afirma que a mídia constrói a realidade e que o telespectador percebe essa realidade como verdade, não como construção. Nestes termos, o conteúdo biopolítico sobre morte e vida é facilmente assimilado. Como observa o autor, "supõem-se e acredita-se que as notícias sejam corretas e verdadeiras" (Ibid, p. 55).

Luhmann entende a informação, a matéria-prima dos meios de comunicação, como algo indispensável ao processo comunicativo ${ }^{7}$ que, por sua vez, entende como indispensável à sociedade. Para o autor, a sociedade não pode ser pensada sem

\footnotetext{
${ }^{7}$ No contexto da ação comunicativa, Habermas (1987) diz que os indivíduos, aos interagirem, coordenam suas ações. Ele observa que, do conhecimento que as pessoas partilham do mundo objetivo, depende o sucesso ou o insucesso de suas ações conjuntas. Para o autor, a prática comunicativa cotidiana se dá no contexto "do mundo da vida que [os falantes] compartilham intersubjetivamente" (1987, p. 30-31).
}

Em Tese, Florianópolis, v. 12, n. 1, jan./jul., 2015. ISSN: 1806-5023 


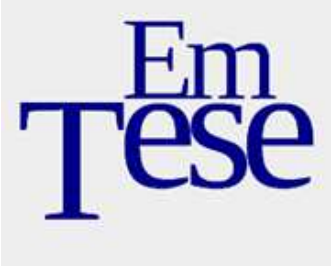

comunicação, e a comunicação não pode ser pensada sem a sociedade ${ }^{8}$. "A comunicação bifurca a realidade: cria duas versões do mundo, a do sim e a do não, obrigando assim, a tomada de uma decisão" (LUHMANN, 1995, p. 303).

\section{Considerações finais}

Como destacado nas sessões anteriores, a partir do século 18 houve uma inversão de valores em termos biopolíticos: o direito de causar a morte, conferido ao soberano e explicitado no suplício, transformou-se em uma espécie de dever de causar a vida, com o objetivo de otimizá-la em termos econômicos. Ou seja: o registro político mudou da morte para a vida, mas o controle sobre o público permanece o mesmo.

$\mathrm{Na}$ prática, esta mudança de registros aparenta ter ao menos duas consequências: (1) o surgimento de um novo tipo de habitus, definido por Bourdieu (2005, p. 191) como "sistema das disposições socialmente constituídas que, enquanto estruturas estruturantes, constituem o princípio gerador e unificador do conjunto das práticas e das ideologias características de um grupo de agentes"; e (2) o surgimento de um novo tipo de racismo, entre quem tem o corpo ideal (forte, magro, exercitado e disposto, como o soldado do século 18) e quem não o tem (neste grupo estão os obesos, os baixinhos, a mulher que não tem cabelo liso etc).

No caso do novo habitus (1), a principal característica é o fato de a sociedade excluir de sua rotina aquilo que leva à morte (como comer gordura trans), ao mesmo tempo em que insere em seu cotidiano aquilo que promove a vida (como fazer atividade

\footnotetext{
${ }^{8}$ Berchmann \& Stehr (2001, p. 193) dizem que Luhmann via a sociedade como sociedade da comunicação. "A comunicação se torna a estrutura básica da sociedade, na qual a relação entre comunicação e sociedade é circular: não existe comunicação sem sociedade, assim como não existe sociedade sem comunicação". Luhmann via a comunicação como uma síntese de informação (uma referência externa), de transmissão (auto-referência) e de compreensão (condição para a transferência de sentido em comunicações ulteriores).
} 


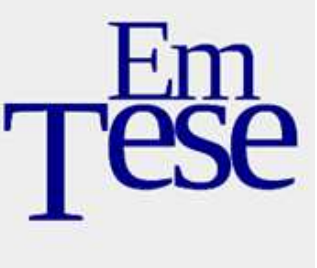

física). O problema é que, aparentemente, isto se dá de maneira mecânica e irrefletida. Não está dito e assimilado que, no fim, o processo busca promover um corpo economicamente eficiente. Aqui, eficiência tem a ver com disposição para o trabalho ${ }^{9}$.

Este habitus moderno não provoca mudanças só na rotina dos indivíduos. Em um ciclo vicioso, ele também altera o perfil dos meios de comunicação, de onde partem as regras desse novo modo de ser e agir. Para citar três exemplos, ele reconfigura a programação da tevê (há programas exclusivos sobre essa temática); altera o conteúdo do jornal (já há editorias chamadas Vida e Saúde); e cria revistas temáticas (saiba como perder três quilos em uma semana é a manchete de muitas delas).

Em outra frente, esta onda em favor da vida acaba por levar (2) a um novo tipo de racismo. Não entre brancos e negros. Não entre humanos e não-humanos ${ }^{10}$. Mas entre quem tem um corpo economicamente eficiente e quem não o tem.

Foucault (2005, p. 228) diz que o nazismo, o pior regime racista da contemporaneidade, foi possível a partir do biopoder. " $\mathrm{Na}$ medida em que seus mecanismos são usados para exercer o direito soberano de fazer morrer ou deixar viver, a biopolítica se converte em uma política de morte".

Para o autor, a teoria evolucionista, de Darwin, e a teoria da degeneração, de Morel, conferiram sentido biológico ao conceito de raça. Com isso, a função de morte do direito soberano já não está dirigida ao inimigo político, mas ao biológico. Nesse contexto, observa ele, a destruição das outras raças é só um dos objetivos do racismo; o outro é a regeneração da própria raça, mesmo que ela seja exposta à morte.

Foucault (Ibid, p. 230-304-309) sustenta que "o racismo moderno não é nem uma velha tradição, nem uma nova ideologia, mas uma tecnologia do poder”. Ele

\footnotetext{
${ }^{9}$ Válido lembrar que, na perspectiva de Marx (1989, p. 158), "o trabalho alienado aliena do homem o seu próprio corpo, tal como a natureza fora dele".

${ }^{10} \mathrm{O}$ termo racismo é usado em estudos evolucionistas, sobretudo pelos defensores dos animais. Refere-se ao desenvolvimento da raça humana em detrimento das demais. Singer (2004) diz que atos contra o bemestar dos animais nos dias de hoje vêm da antiguidade grega, e que o cristianismo deixou os não-humanos fora do âmbito da compaixão. Para o autor, só o rompimento com mais de 2 mil anos de pensamento ocidental relativo aos animais poderemos construir uma base sólida para a extinção dessa exploração.
} 


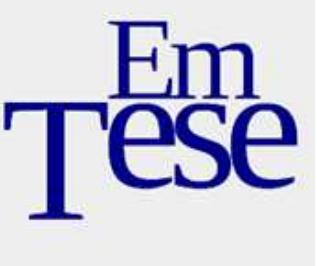

observa que, apesar de o racismo ser mais antigo que a época do soberano, "o que o inseriu nos mecanismos de Estado foi mesmo a emergência desse biopoder".

\footnotetext{
Como, nessas condições, é possível, para um poder político, matar, reclamar a morte, pedir a morte, mandar matar, dar ordem de matar, expor à morte não só seus inimigos, mas seus próprios cidadãos? Como esse poder que tem essencialmente o objetivo de fazer viver pode deixar morrer? Como exercer o poder da morte, a função da morte, num sistema político centrado no biopoder? É aí que intervém o racismo (FOUCAULT, 2005, p. 304).
}

Afirma Foucault que o racismo é "o meio de introduzir, nesse domínio da vida de que o poder se incumbiu, um corte: o corte entre o que deve viver e o que deve morrer" (Ibid, 304). Ele sustenta que a primeira função do racismo é "fragmentar, fazer censuras no interior desse contínuo biológico a que se dirige o biopoder"; a segunda é estabelecer uma espécie de relação outrora guerreira (para viver, é preciso que você massacre seus inimigos) em sentido biológico: “Quanto mais as espécies inferiores tenderem a desaparecer, quanto mais os indivíduos anormais forem eliminados, menos degenerados haverá em relação à espécie, mais eu viverei, mais forte serei, mais vigoroso serei, mais poderei proliferar" (FOUCAULT, 2005, p. 305).

Para o autor de Vigiar e Punir, "tirar a vida, o imperativo da morte, só é admissível, no sistema de biopoder, se tende não à vitória sobre os adversários políticos, mas à eliminação do perigo biológico e ao fortalecimento da própria espécie ou da raça. A raça, o racismo, é a condição de aceitabilidade de tirar a vida numa sociedade de normalização". "O racismo é ligado ao funcionamento de um Estado que é obrigado a utilizar a raça, a eliminação das raças e a purificação da raça para exercer seu poder soberano" (FOUCAULT, 2005, p. 306).

\section{Referências}

BECHMANN, Gotthard \& STEHR, Nico. Niklas Luhmann. Tempo Social, nov. 2001, vol $13, n^{\circ} 2$, p. $185-200$

Em Tese, Florianópolis, v. 12, n. 1, jan./jul., 2015. ISSN: 1806-5023 


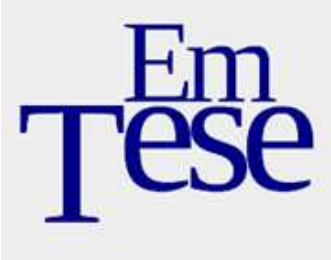

BOLTANSKI, Luc; CHIAPELLO, Éve. O novo espírito do capitalismo. São Paulo: Martins Fontes, 2009

BOURDIEU, Pierre. A economia das trocas simbólicas. São Paulo: Perspectiva, 2005

BRIGGS, Asa; BURKE, Peter. Uma história social da mídia: de Gutenberg à internet. 2. ed. Rio de Janeiro: Zahar, 2006

FONSECA, João José. Metodologia da pesquisa científica. Fortaleza: UEC, 2002.

FOUCAULT, Michel. História da sexualidade I: a vontade de saber; tradução de Maria Thereza da Costa Albuquerque e J. A. Guilhon Albuquerque. 22. ed. Rio de Janeiro: Graal, 2012.

. Vigiar e punir: história da violência nas prisões; tradução de Raquel Ramalhete. 41. ed. Petrópolis: Vozes, 2013.

Em Defesa da Sociedade. São Paulo: Martins Fontes, 2005.

. Segurança, Território, População. São Paulo: Martins Fontes, 2009

HABERMAS, Jurgen. Teoria da ação comunicativa I - Racionalidade da ação de da racionalização social. Madri: Taurus, 1987.

HOBBES, Thomas. Leviatã. São Paulo: Martins Fontes, 2003.

KOVACH, Bill; ROSENSTIEL, Tom. Os elementos do jornalismo: o que os jornalistas devem saber e o público exigir. 2. ed. São Paulo: Geração Editorial, 2003

LUHMANN, Niklas. A realidade dos meios de comunicação; tradução de Ciro Marcondes Filho. São Paulo: Paulus, 2005.

Herder, 1997.

La sociedad de la sociedad; tradução de Javier Torres Nafarrate. México:

MARX, Karl. Trabalho alienado e superação positiva da autoalienação humana (Manuscritos Econômico-Filosóficos). FERNANDES, Florestan. Marx e Engels. 3 ed. São Paulo: Ática, 1989.

POMBO, Olga. Epistemologia da Interdisciplinaridade. Conferencia proferida no Colóquio "Interdisciplinaridade, Humanismo e Universidade", promovido pela Cátedra Humanismo Latino, Porto, 2007. 


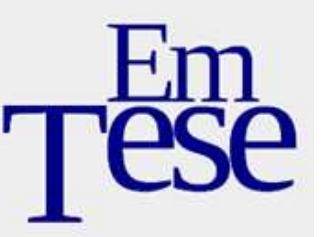

POSTMAN, Neil. Tecnopólio: a rendição da cultura à tecnologia. São Paulo: Nobel, 1994.

SINGER, Peter. Libertação animal. Porto Alegre: Lugano, 2004

WEBER, Max. A ética protestante e o espírito do capitalismo; tradução de Vinicius Eduardo Alves. 4. ed. São Paulo: Centauro, 2013.

O político e o cientista. Lisboa, Presença, 1979.

Em Tese, Florianópolis, v. 12, n. 1, jan./jul., 2015. ISSN: 1806-5023 


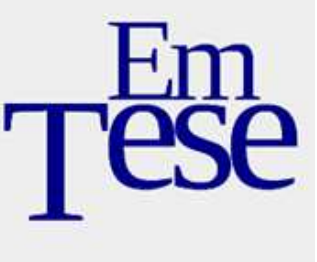

\title{
Direito de morte e dever de vida: a mídia como canal de tecnologias políticas
}

Resumo: Este artigo trata de duas tecnologias políticas descritas por Michel Foucault: o direito de morte e o dever de causar a vida. O texto resgata dois temas tratados pelo autor (suplício e biopoder) para pensar dois eventos em voga na mídia: o fuzilamento de dois traficantes brasileiros na Indonésia (direito de morte?) e a valorização do conteúdo em prol de uma vida saudável (dever de causar a vida?). O manuscrito baseia-se em levantamento bibliográfico. $\mathrm{O}$ ensaio conclui que a interação dessas tecnologias políticas promove (1) uma espécie de habitus moderno e (2) um novo tipo de racismo. Nos dois casos o objetivo é produzir corpos economicamente saudáveis.

Palavras-Chave: Suplício. Bipoder. Foucault.

\section{Right to death and duty of life: the media as political technologies channel}

\begin{abstract}
This article presents two political technologies described by Michel Foucault: the right to cause death and the power of causing life. The text rescues two subjects treated by the author (torture and biopower) to discuss two events in vogue in the media: the firing traffickers in Indonesia (right to cause death) and the news of progress towards a healthier life (power cause life). The manuscript concludes that the interaction of these political technologies promotes a kind of modern habitus, which produce politically docile bodies and economically profitable.
\end{abstract}

Keywords: Torment. Biopower. Foucault.

Recebido em: 05 de Maio de 2015

Aceito para publicação em: 22 de Junho de 2015 